\title{
Emotion Regulation, Cognitive Closure and Compliance of Spouses in Relationship Conflict
}

\author{
Roni Laslo-Roth \\ School of behavioral Sciences, Peres Academic Center, Rehovot, Israel \\ SCE - Shamoon College of Engineering, Ashdod, Israel \\ Eyal Rosenstreich \\ School of behavioral Sciences, Peres Academic Center, Rehovot, Israel
}

\begin{abstract}
This study was aimed to examine the relationships between emotion regulation and compliance among spouses in conflict. Furthermore, because compliance in conflict situations has been associated with individual differences in cognitive closure and emotions, we examined how these factors modulate the effect of emotion regulation on compliance. To this end, 70 praticipates, randomly assigned to reappraisal and control groups, reported the influence tactics they would comply, their affective state and their cognitive closure level. Results indicated that as compared to control, reappraisal strengthened the tendency to comply during conflict and that this effect was stronger among participants with low cognitive closure. Moreover, the interaction between emotion regulation and cognitive closure on harsh influence tactics was mediated by inward-directed negative affect, suggesting that the reappraisal instruction promoted better resiliency to negative affect among high cognitive closure participants. We discuss the role of emotion regulation techniques in treatment and in interpersonal relationships.
\end{abstract}

Keywords: Emotion regulation, conflict, compliance, cognitive closure.

\section{INTRODUCTION}

Conflict is an avoidable part of romantic relationship. Research has found that spouses engaged in conflicts approximately twice a week (Canary, Cupach, and Serpe, 2001). Those conflicts can either weaken or strengthen the relationship, it can be destructive, causing resentment, hostility, separation or divorce, but it can also be productive, creating understanding, closeness and respect for one another. The determining factor in healthy and unhealthy relationships is how conflicts get resolved, and not necessarily their frequency in the relationship (Igbo, Grace, \& Christiana, 2015). Emotions take a critical role in effecting conflict management style; negative emotions lead to aggressive management style while positive emotions lead to softer, friendlier, management style (Laslo-Roth \& Schwarzwald, 2016). If one lack the emotional abilities needed to manage negative emotions, to feel empathy and to be self-aware to those feelings, then his ability to preserve meaningful relationship is hurt (Gottman, Coan, Carrere \& Swanson, 1998). In this study, we investigated how an adaptive emotion regulation technique-reappraisal—affects conflict behavior in romantic relationships.

\section{Conflict management}

Spousal conflict arises between the two parties in a romantic relationship over any or all conceivable areas of interaction such as economic activities, child-rearing, performance of household tasks, leisure pursuits, decision making, religious, social activities, sex relations, in laws and so on (Kirchler, 2001). Conflicts are not unhealthy by their nature; when managed 
properly, they can uncover problems, lead to joint solutions, and promote closeness and satisfaction from the relationship. However, if conflicts are dealt in a hostile or competitive way, when spouses cannot compromise, and don't allow themselves to try to understand their partner and comply with some of the partner's requests, conflicts can be destructive, causing resentment, hostility, separation or divorce (Gottman, Coan, Carrere \& Swanson, 1998). The implications of such conflicts are hard and have an impact on broader circles besides the spouses themselves, such as on children, relatives and the society at large (Igbo, Grace, \& Christiana, 2015).

The determining factor in healthy relationships is the way conflicts are resolved, rather than the frequency conflicts occur. Hence, in order to sustain continual healthy romantic relationship, spouses must learn to adopt appropriate conflict resolution strategies to resolve various aspects of conflicts challenging their union (Ben-Naim, Einav, Laslo-Roth, \& Margalit, in press). Conflict resolution is an act of finding a solution to a conflict in a way that both parties of the conflict are mutually satisfied with the outcome of a settlement and the conflict resolved in a true sense (Burton, 1990).

There are various strategies by which spousal conflicts might be resolved (Igbo, Grace, \& Christiana, 2015); in the focus of the present study is the Interpersonal Power Interaction Model (Raven, 1992; Raven, Schwarzwald, \& Koslowsky, 1998). This model describes how an individual chooses an influence tactic or rather complies with the influencing agent and specifies cultural-social, situational and personal factors, as well as cost-benefit considerations that determine influence tactics preference and compliance. In addition, the model defines eleven influence tactics (power bases) available to the influencing agent. These influence tactics reflect two distinct strategies toward the target. The first include soft influence tactics, which assumes that the influencing agent views the target as an equal partner without applying undue pressure on the target. On the other hand, the second approach is composed of harsh influence tactics, showing inequality, stressing the target's inferiority while pressuring him/her, and narrowing the ability to make free decisions.

\section{The role of emotions in conflicts}

Although the traditional approach views conflict management as a rational process of decisionmaking (Montes, Rodriguez \& Serrano, 2012), recent approaches shifts the spotlight to the emotional component as an involving factor that may help in understanding conflict behavior (Laslo-Roth \& Schwarzwald, 2016). It is argued that emotions assist in conceptualizing the conflict as well as in directing behavior (Morris \& Keltner, 2000). For example, Montes, et al. (2012) have shown that in conflict situations people do not necessarily act in a rational manner, but rather are influenced by emotions. Studies have shown quite consistently that negotiators experiencing positive emotions tend to be more cooperative and conciliatory, whereas negotiators experiencing negative emotions tend to be more competitive and reluctant to comply (Van Kleef, De Dreu, \& Manstead, 2004).

Since it seems that the emotional experience in the conflict has a central role in determine how people choose to manage conflicts, it can be assumed that emotion regulation (the processes whereby people control and manage their own emotions) is an effective mean in dealing with relationship conflicts. The most commonly studied adaptive regulation strategy is cognitive reappraisal, which is the ability to evaluate situations in a way that alter its emotional meaning (Gross, 1998; Koval et al. 2014).

A recent study (Ben-Naim, Hirschberger, Ein-Dor, \& Mikulincer, 2013) explored the impact of reappraisal on the physiological arousal, self-reported emotional experience, and emotional 
behavior of spouses engaging in a relationship conflict. Couples were asked to rate the degree to which they disagree with their partner on typically conflicts issues in close relationships and were asked to discuss an issue rated by both partners as high-level disagreement in their relationship. Each participant received instructions to his earphone according to one of threemanipulation condition. In the reappraisal condition participants were asked to keep in mind that all couples have conflicts and that discussing them can make it hard to remember the positive aspects of the partner and the relationship. In the suppression condition, participants were asked to inhibit the expression of emotion through their facial expressions and tone of voice so that their partner will not know they are experiencing any emotions at all. Finally, in the control condition participants were asked to prepare for the conversation by remembering the major issues related to the conflict topic. Spouses then engaged in a 15-minute conversation on their selected area of disagreement. During the conversation, sensors attached to their bodies measured their autonomic nervous system responses and their emotional behavior was analyzed. When the conversation ended, participants completed a questionnaire assessing their emotions during the conversation. Results revealed that as compared to control, reappraisal instructions decreased cardiovascular arousal, negative affect, and negative interpersonal behavior.

Not only that it was well established that reappraisal weakens negative emotions (Gross, 2002), studies also demonstrated that negative emotions leads to negative judgments and negative interpersonal behavior in conflict situation (Laslo-Roth \& Schwarzwald, 2016; Van Kleef et al., 2004). In one study (Laslo-Roth \& Schwarzwald, 2016) the mediated role of negative emotion between conflict types and conflict behavior was examined among 240 managers (in relation to their employees). It was found that managers perceptions concerning the potential damage embedded in the conflict with their subordinates, evoke outwards negative emotions (emotions directed to the environment), but not inwards negative emotions (emotions directed to the self). Hence, the intensity of those outwards negative emotions alone strengthened managers' tendency to use harsh tactics toward their employees.

One important consideration in Laslo-Roth \& Schwarzwald's (2016) study is that negative emotion was not treated as a unitary construct, but rather as consisting of emotions directed inwards towards the self and emotions directed outwards towards the environment. This notion is supported by The Structural Theory of Emotions (De Rivera, 1977; De Rivera \& Grinkis, 1986; De Rivera, Possel, Verette, \& Weiner, 1989) which postulates that emotions may be differentiated according to their locus of attention: emotions that focus on the self, and emotions that focus on the other and surroundings. In particular, internal convergence occurs when negative emotions such as fear or distress are aroused; external extension occurs when negative emotions such as hostility or anger are evoked.

\section{The need for cognitive closure}

Although inwards and outwards negative emotion both play a role in conflict behavior, the extent to which they are manifested may be determined by various traits, as cognitive closure (cf. Kruglanski, 2004). That is, because the need for cognitive closure is the "desire for a firm answer to a question, any firm answer as compared to confusion and/or ambiguity" (Kruglanski, 2004, p. 6), people high in cognitive closure experience intolerance toward ambiguity; prefer quick, unequivocal solutions, and express resistance to change. In contrast, people with low cognitive closure are characterized by a continued quest for valid information and detailed diagnosis even at the risk of ambiguity and delayed solutions. During conflict, these differences may be manifested in different level of inwards negative emotions, as high cognitive closure people, in compresence to low cognitive closure, will experience more 
negative inwards emotions during conflicts that drive from internal discomfort toward ambiguous situations (Kruglanski, 2004).

Different levels of cognitive closure may be important determinant of conflict behavior. The internal discomfort facing high cognitive closure people when facing conflict situations may motivate them to prefer a competitive, non-flexible approach. In contrast, those with low cognitive closure, who are more tolerant of opposing opinions, may be more receptive to compromise (Shan, Kruglanski, \& Thompson, 1998). Indeed, research has demonstrated that a high need for cognitive closure, reduces the tendency to compromise in negotiation (De Dreu, Koole, \& Oldersma, 1999) and highlight the tendency to act in an aggressive, competitive behavior that attempts to force compliance on the opposing party (Golec \& Federico, 2004). In a recent study, which examined managers and subordinates in five Italian companies, it was found that subordinates with high need for cognitive closure reported greater tendency to comply with harsh influence tactics, but lower willingness to comply with soft influence tactics versus their low cognitive closure counterpart's (Bélanger, Pierro, \& Kruglanski, 2015).

The present study was aimed to further examine the effect of emotion regulation techniques on the compliance in conflict interactions between spouses, with a focus on cognitive closure (Pierro, Kruglanski, \& Raven, 2012). In particular, while most studies focused on the association between emotion regulation and the influence strategy chosen, the association between emotion regulation and compliance was scarcely studied. One developmental study found that infants that were not able to regulate their frustration demonstrated less compliance to their parents as toddlers (Stifter, Spinrad, Braungart, \& Rieker, 1999); toddlers who showed low level of emotion regulation behaviors as infants (low levels of communicative behaviors or self-comforting) were more likely to exhibit noncompliance behaviors as avoidance (escape and scanning behaviors) and defiance (refuse to comply while displaying an angry or whiny tone of voice and aggressive behavior).

Taken altogether, the present study was designed to examine the joint effect of emotion and cognitive closure on behavior in conflict situations. To this end, an experimental design was carried in order to examine whether the interaction between emotion regulation and cognitive closure will result in different conflict management as a function of the type of negative emotion evoked by the conflict (inwards vs. outwards). That is, because high-closure tendency is to feel discomfort and threaten by conflict situations, it is likely that they will feel more inwards negative emotion when facing conflicts and will be more inclined to end the threaten conflict situation by complying to harsh tactics which are characterize in quick ending of the conflict. It is also likely that high closure people will most benefit from the reappraisal regulation technique that assist them to exhibit openness to new ways of reflecting on the conflict; inwards negative emotion will be thus reduced, and their tendency to comply to harsh tactics will be increased. Therefore, it was hypothesized that:

H1: Cognitive closure will moderate the effect of emotion regulation on inwards negative emotion. Specifically, as compared to control, reappraisal intervention will decrease inwards negative affect, but this effect will be more or solely evident among participants with high cognitive closure.

H2: The effect of emotion regulation X cognitive closure interaction on harsh and soft influence tactics will be mediated through the level of inwards, but not outwards, negative affect. Put differently, a mediated moderation model was predicted (see Figure 1 for illustration). 


\section{Participants}

\section{METHOD}

The sample consisted of 70 participants (Age: $M=31.54, S D=9.94$, ranged 19-61; 43 female, 27 male), all were in a romantic relationship and were fluent Hebrew speakers. Nearly half of the participants were married (46\%), 25\% were cohabited, and the remaining participants reported to be in a relationship without cohabiting (29\%). The average relationship length was 88.3 months $(M d=125.5)$. The sample was gathered with the aid of seven research assistants, using a convenience sampling method. All participants gave their written consent to participate.

\section{Design and materials}

The study employed experimental and correlational research methods, with Emotion regulation strategy manipulated between subjects, and influence tactics, affect, and cognitive closure as measured variables.

Emotion regulation manipulation. Each participant was randomly assigned to one of two conditions, reappraisal or neutral regulation instructions. Previous research has used these instructions to induce the emotion regulation strategies of reappraisal (e.g., Richards, Butler, \& Gross, 2003). In the reappraisal condition $(N=34)$, participants were informed that (a) "The study is designed to understand the link between the kind of mindset a person adopt and his behavior in conflict situations"; (b) "We would like for you to prepare for the conversation by writing two of the major issues related to the conflict topic you will be discussing"; and (c) "We would like for you to keep in mind that all couples have conflicts and that discussing them can make it hard to remember the positive aspects of the partner and the relationship. Try to remember some of the positive aspects of your relationship, as well as some of the good times you have had together". In the control condition $(N=36)$ participants received the following instructions: (a) "The study is designed to understand how couples communicate in conflict situations"; and that (b) "We would like you to prepare for the conversation by writing two of the major issues related to the conflict topic you will be discussing". Thus, no regulatory instructions were given.

Power Tactics Scale. A modified version of the Bui et al. (1994) scale describing influence tactics behaviors was used (Schwarzwald, Koslowsky \& Ben-Izhak Nir, 2008); the scale is particularly appropriate for this study as it uses Raven's (1992) social power framework for understanding power behavior in romantic relationships. Respondents were asked to think about a specific conflict in their romantic relationship. They were presented with 14 statements describing different influencing tactics that can be used by their spouse. Participants were asked to indicate, for each tactic, what is the probability that the use of this tactic by their spouse will lead them to comply (scale ranging from 1 "very low probability" to 7 "very high probability"). The literature indicates that influence tactics are not entirely independent but rather can be subsumed under two or three factors (Bui et al., 1994). Furthermore, Koslowsky and Schwarzwald (2001) argued that there is a methodological advantage in using factor scores rather than individual tactics as they provide measures that are more reliable and allow comparisons among studies where different tactics were used. In our study, we use a two-factor solution (soft versus harsh tactics), that is more commonly observed in the power literature (Schwarzwald et al., 2008). The harsh tactics include six items such as "I will comply my spouse request if he will offer to do something pleasant for me, if I would comply". The soft tactics include eight items such as "I will comply my spouse request if he will express appreciation for my compliance". The power tactic scale was used in previous studies and was reported to be valid and reliable (Schwarzwald et al, 2008). In the present study, Cronbach's alphas were .73 for harsh and .75 for soft tactics. 
The Couple's Problem Inventory (CPI). A modified version of the Gottman, Markman, \& Notarius (1977) describing conflicts areas between spouses was used (Ben-Naim et al., 2013). This measure was used to assess participants' most important conflict issues with their spouses. Participants were asked to rate the degree to which they disagree with their partner on 14 issues that are typically a source of disagreement in close relationships (e.g., finances, sex, leisure time, relatives). Participants rated their level of disagreement on a scale of $0-100$, such that higher scores indicate greater levels of disagreement. Based on participants' responses, the experimenter chose the most conflictual issue and asked the participants to address to this specific issue in the following questionnaires.

Positive and Negative Affect Scale (PANAS). This measure was used to assess participants' emotions evoked by the conflict. To this end, the participant was asked to indicate the degree to which the conflict evoked each emotion, on a scale ranging from "absolutely not" (1) to "absolutely yes" (5). This request was followed by eighteen emotions: nine negative emotions such as "distress" and "upset" and nine positive emotions as "enthusiasm" and "interest". These emotions were taken from the Hebrew version (Lipovetzky et al., 2007) of the original questionnaire (Watson, Clark, \& Tellegen, 1988). In the present study, Cronbach's alphas were .82 for general negative affect, .77 for inwards negative affect, and .78 for outwards negative affect. Cronbach's alpha of positive affect was .78.

Cognitive Closure Scale. This questionnaire measures attitude toward information and tolerance for ambiguity (Pierro \& Kruglanski, 2005). To this end, we used the Hebrew version of the questionnaire (Laslo-Roth \& Schwarzwald, 2016). The questionnaire comprised 14 items, such as "In cases of ambiguity, I prefer an immediate decision, regardless of what the decision may be". Participants were asked to indicate agreement with each statement on a scale ranging from "absolutely disagree" (1) to "absolutely agree" (6). The cognitive closure scale was widely used in previous studies and was reported to be valid and reliable (Webster \& Kruglanski, 1994). In the present study, Cronbach's alpha was .74.

Demographics. The questionnaire contained items related to gender, age, education, family status, time in relationship, and religiosity.

\section{Procedure}

Participants who agreed to participate in the study received a Hebrew version of the Couple's Problem Inventory (CPI; Gottman, Markman, \& Notarius, 1977), and were asked to rate the degree to which they disagree with their partner on issues typically a source of disagreement in close relationships. Based on participants' responses, the experimenter chose the most conflictual issue and asked the participants to address to this specific issue in the following questionnaires. The participant was then randomly handed with a booklet containing the research questionnaires, which opened with one of the two emotion regulation instructions conditions. Those instructions were followed by the power tactic scale, PANAS, cognitive closure scale, and demographic questionnaire. Order of presentation was constant for all participants. Upon completion, participants handed back the booklet to the experimenters, and were thanked.

\section{Preliminary analyses}

\section{RESULTS}

First, total scores were calculated for influence tactics, positive and negative affect, and cognitive closure; total scores were calculated as mean rating in the relevant items of each questionnaire. Then, Pearson correlations were calculated between the continuous variables. Pearson coefficients and descriptive statistics are presented in Table 1. 
Table 1 reveals that background variables as age and conflict severity were not correlated with the research variables; however, relationship length was marginally correlated with positive affect score. Harsh strategy score was also correlated with negative affect score, showing that high harsh scores were accompanied by more negative affect.

\section{The effects of emotion regulation}

Next, we turned to compare the differences between the emotion regulation groups (control, reappraisal) in the research measures. Specifically, it was examined whether as predicted, the reappraisal group showed higher scores in the influence tactics subscales as compared to controls. To this end, five one-way analyses of covariance (ANCOVAs) were conducted with emotion regulation grouping as the independent variable and harsh strategy, soft strategy, negative affect, positive affect, and cognitive closure scores as the dependent variables. In all analyses, conflict severity was controlled. Adjusted means and inferential statistics are presented in Table 2.

Table 2 reveals that the groups differed in harsh and soft strategy scores, such that the reappraisal group exhibited elevated compliance ratings with both harsh and soft tactics. Furthermore, Table 2 reveals that the groups did not differ in their negative and positive affect scores. Finally, the groups differed in their cognitive closure scores, with the reappraisal group scoring slightly higher than controls.

\section{Examination of the mediated moderation model}

Next, we examine whether cognitive closure moderated the effect of emotion regulation on harsh and soft strategy scores, and whether inwards or outwards negative affects mediated this effect to some extent. To this end, the emotion regulation groups (reappraisal, control), cognitive closure, inwards/outwards negative affect, and harsh and soft strategy scores were ztransformed. In addition, a Group X Cognitive closure interaction was calculated by multiplying the transformed variables. Finally, these variables were submitted to two hierarchical regression analyses, in which the first block was entered with sex, age, relationship length, and conflict severity; the second block was entered with the transformed grouping and cognitive closure variables; the final block was entered with the interaction. Outwards negative affect (ONA) served as the predicted variable in the first analysis, whereas inwards negative affect (INA) was the predicted variable in the second. Four more hierarchical regression analyses were conducted, two with harsh compliance as the predicted variable and two with soft compliance as the predict variable. The purpose of these analyses was to examine the unique contributions of ONA and INA to the prediction of the compliance rate with each tactic, and to identify markers of mediation (i.e., a reduction in the coefficients of one of the other predictors following the enter of ONA or INA). Standardized regression coefficients are presented in Table 3.

As for ONA or INA as the predicted variables, the analyses revealed that both were predicted solely by the interaction between emotion regulation and cognitive closure. Examination of the simple effects revealed that the interaction patterns were similar for ONA and INA. Specifically, as association between cognitive closure and negative affect was observed among controls (for ONA: $B=.756, p=.007$; for INA: $B=.983, p=.001$ ) but not among the reappraisal group (for ONA: $B=-.377, p=.098$; for INA: $B=-.379, p=.101$ ). This consolidates with our notion that without the cultivation of an adaptive emotion regulation technique, high cognitive closure will be accompanied by more inwards and outwards negative affect. In particular, whereas control and reappraisal groups did not differ in their ONA or INA when cognitive closure rates were low or medium $(.069<p<.459)$, controls exhibited more negative affect than the reappraisal group when cognitive closure was high ( $p=.008$ and $p=.002$ for ONA and INA, respectively). 
As for the compliance with harsh and soft tactics as the predicted variables, Table 3 reveals that the sole predictor of both variables was the emotion regulation grouping, with-as reported earlier - the reappraisal group exhibiting more compliance with both tactics as compared to controls. ONA did not predict either compliance with harsh or soft tactics, suggesting that no mediation was evident. In contrast, INA positively predicted compliance with harsh, but not with soft, tactics, such that higher INA rates were accompanied with higher tendency to comply with harsh tactics. However, because the addition of INA to the model did not affected the coefficient of the emotion regulation, it seems that INA did not mediate the association between emotion regulation and compliance with harsh tactics $(B=-.072,95 \%$ BootLLCI $=-.275$, BootULCI $=.051$ ). Nonetheless, because INA was predicted by the interaction between emotion regulation and cognitive closure, mediated moderation was examined. Indeed, using PROCESS macro for SPSS (Hayes, 2013) it was confirmed that mediated moderation relation existed between the research variables (Index of moderated mediation $=$ $.398,95 \%$ BootLLCI $=-.923$, BootULCI $=-.063$ ). The final model is presented in Figure 2 .

\section{DISCUSSION}

The present study was designed to investigate the effect of emotions regulation on conflict behavior, and whether this effect was modulated by cognitive closure. Based on theory and prior research, we hypothesized that compared to control, reappraisal would reduce inwards negative affect among high cognitive closure people during conflicts situations, and that this abridged negative emotion will result in increased tendency to comply with harsh tactics.

Overall, the results revealed several distinct patterns on the influence of reappraisal on negative emotions and compliance. First, our data replicated previous findings, showing that negative emotion increased the tendency to comply with harsh tactics (Tal, Schwarzwald \& Koslowsky, 2015; Laslo-Roth \& Schwarzwald, 2016). Second, in line with previous findings, it was found that the effect of emotion regulation and cognitive closure on conflict behavior was mostly limited to compliance with harsh tactics (e.g., Laslo-Roth \& Schwarzwald, 2016; Schwarzwald, Koslowsky \& Allouf, 2005).

The innovation in the current study was the incorporation of cognitive closure and subconstructs of negative affect in one model, in order to better understand the effects of emotion regulation on conflict behavior. In contrast to our prediction, the findings revealed a distinct pattern, in which inwards negative affect mediated the interaction between emotion regulation and cognitive closure, on compliance with harsh tactics, such that reappraisal reduced inwards negative emotion which, in turn, lessen the tendency to comply with harsh tactics, but only among high cognitive closure participants. This may be due to a decrease in the heightened inwards negative emotion that typically accompanies high cognitive closure in conflicts, thus allowing these participants to overcome their natural tendency to comply with harsh tactics (cf. Bélanger et al., 2015). Specifically, negative emotions limit the ability to process new information, and promote relaying on familiar behaviors and cognitions (Buehlman, Gottman, \& Katz, 1992) According to this notion, people high in cognitive closure will be more prone to act according to their natural tendencies and to comply with harsh tactics when negative emotions are evoked. Accordingly, instructing them to reappraise their emotions, that is, to shift their attention from negative to positive aspects of the situation, weakens the effects of negative emotion on behavior.

Interestingly, our data revealed two distinct pathways through which emotion regulation affected compliance with harsh tactics. First is the direct pathway, in which reappraisal increased compliance compared to control instructions. The second pathway is the mediated moderation pathway, in which reappraisal decreased inwards negative affect among high 
cognitive closure participants, whereas the decreased negative affect was in turn associated with a decrease in compliance with harsh tactics. It seems, therefore, that when cognitive closure is taken into account, inwards negative affect acts as a suppressor of the effects of reappraisal.

Nevertheless, these seemingly contradicting pathways may not be in fact contradictory; the Interpersonal Power Interaction Model assumes that the choice of conflict behavior serves, among others, as a mean for satisfying personal needs (Koslowsky, \& Schwarzwald, 2009). For example, people with the need for self-esteem prefer to use harsh strategies even in cases where soft strategies are just as effective (Bugental \& Lewis, 1999). Hence, people with low self-esteem may find harsh tactics adaptive in the sense they provide them a boost of selfconfidence as they highlight the upper stand of the influencing agent. For people with high selfesteem, on the other hand, soft tactics are more adaptive as they allow them to preserve good relationship with their environment.

Therefore, "adaptive emotion regulation" is, in this sense, personal and may vary as a function of personal needs, style, and motives and allows individuals to function successfully in their environment by engaging in goal-directed behaviors when faced with a difficult emotion experience (Cutuli, 2014, Gratz \& Tull, 2010). Thus, beneficial results of emotions regulation may be manifested with an increase in compliance with harsh tactics for low need in cognitive closure and with a decrease in compliance to the same harsh tactics for high need of closure. That is, among low cognitive closure, reappraisal may promote cooperation with their partners; among high cognitive closure, on the other hand, compliance with harsh tactics in order to reach closure in the short run may not be satisfying their interests, which may produce more negative emotions toward their partner. For them, decrease in compliance to harsh tactics-compliance produced by negative emotion-may be more beneficial.

The findings obtained in this study demonstrated that personality trait as cognitive closure can moderate the behavioral results of reappraisal. This notion is in line with previous studies which suggested that personality traits may also have an impact on the neural base of reappraisal (Ray, Ochsner, Cooper, Robertson, Gabrieli, \& Gross, 2005). Ray et al. (2005) found that individual differences in rumination, the tendency to focus on negative aspects of the self or one's life, is related to different neural mechanisms involved in using reappraisal to regulate negative affect. Specifically, it was found that when participants were asked to increase their negative emotion, rumination scores correlated with increased activity in the left and right amygdala (which supports encoding of the aversive properties of stimuli) and in the left ventrolateral prefrontal cortex (representing changes in the affective relevance of the stimuli). When participants were asked to decrease their negative emotion, rumination scores correlated with decreased activity in bilateral medial frontal areas that involves in emotion processing, self-referential processing, self-reflective awareness of emotion, reasoning about the mental states of other people, and spontaneous stimulus-independent thought. The researches explain these findings in that rumination reflects a general enhanced tendency to keep representations of emotionally evocative thoughts and to use these representations to increase emotional responding.

Similarly, the joint effect of the need for closure and reappraisal may recruit different neural machinimas that lead to different behavioral results. As in rumination, cognitive closure enhances inwards negative thoughts stem from the conflict itself, which may lead individuals to comply with harsh tactics providing quick ending to the conflict. The preference to comply with harsh tactics satisfies their personal need to avoid an uncomfortable ambiguous situation (Bélanger et al., 2015). Altogether, because this is, to the best of our knowledge, the first study 
to examine the effects of reappraisal on compliance as a function of cognitive closure and inwards negative affect, further study is required is order to fully understand this pathway.

\section{Limitations, implications and future directions}

Three caveats limit the ability to generalize our findings. First, the current study focused on conflict between spouses, with an emphasis on self-regulation during the conflict. Although self-perspective of emotion regulation was mainly investigated in the emotion regulation literature over the past decades, it was suggested recently that interpersonal emotion regulation may be important for better understanding of interpersonal conflict (Reeck, Ames, \& Ochsner, 2016). Specifically, Reeck et al. argued that the regulation strategy implemented by one spouse may modulate the perception of the conflict by the other spouse and hence his/her emotional response. In the context of the present study, it would be interesting to examine conflict behavior of one spouse thinking on his partner emotion.

A second limitation lies in that only one emotion regulation strategy was manipulated, reappraisal. Critically, although this strategy is the most commonly investigated adaptive regulation strategy in the emotion regulation literature, other techniques promote regulation through social-oriented emotion awareness. For example, acceptance or loving-kindness meditation-based interventions may be an effective manner to reduce negative affect and to induce other-focused concern (Trautwein, Naranjo, \& Schmidt, 2016). Therefore, employing such intervention in comparison with reappraisal may shed brighter light on the role of emotion in conflict behavior. It is also interesting to investigate less adaptive regulation strategies as suppression, the attempts to hide, reduce, or shorten the behavioral expression of emotions (Gross, 1998; Koval et al. 2014), and its effect on behavior and inwards/outwards negative emotions. Because emotion regulation comprised of a wide variety of techniques (Gross, 1998), future research should investigate the effects of those techniques on conflict behavior.

Finally, the third caveat lies in the notion that reappraisal frees attentional resources that were obtained by the negative affect. Alternatively, one may argue that the effects observed in this study were due to changes in anxiety as a function of reappraisal. That is, reappraisal may have decreased the anxiety high-closure people felt in the presence of an ambiguous, threatening, situation as conflicts, thus enabling them to more easily comply with harsh tactics. This notion is in line with previous studies which reported reappraisal to decrease fear in claustrophobic penitents and improve their functioning (Kamphuis, \& Telch, 2000). Nonetheless, although we cannot determine that the effects of emotion regulation were due to an increase in the availability of attentional resources rather than to a decrease in anxiety, anxiety itself is a factor well known to deplete cognitive resources (e.g., Berggren \& Derakshan, 2013). Therefore, our notion of cognitive benefit after reappraisal instruction may be still valid even when anxiety is taken into account.

To conclude, the findings reported in this study show that reappraisal and negative affect may not have a unitary effect on conflict behavior, but rather have a differential effect varying as a function of cognitive closure. This notion can be useful in treatment, with therapists giving more synchronized instruction to the treatment goals. That is, if the treatment goal is to reduce negative emotions directed toward the spouse or to reduce fear and avoidance from conflicts, reappraisal should be employed while considering the patient's cognitive closure.

\section{References}

Bélanger, J. J., Pierro, A., \& Kruglanski, A. W. (2015). Social power tactics and subordinates' compliance at work: The role of need for cognitive closure. Revue Européenne de Psychologie Appliquée/European Review of Applied Psychology, 65(4), 163-169. doi: http://dx.doi.org/10.1016/j.erap.2015.05.001 
Ben-Naim, S., Einav, M., Laslo-Roth, R. \& Margalit, M. (In press). Hope in the Family: Individual Differences in Parenting Stress, Personal Resources and Coping. In Cohen, F. L (Eds.). Hope: Individual Differences, Role in Recovery and Impact on Emotional Health. Nova Science Publishers, NY.

Berggren, N., \& Derakshan, N. (2013). Attentional control deficits in trait anxiety: why you see them and why you don't. Biological Psychology, 92(3), 440-446.

Bugental, D. B., \& Lewis, J. C. (1999). The paradoxical misuse of power by those who see themselves as powerless: How does it happen? Journal of Social Issues, 55, 51-64.

Bui, K. V. T., Raven, B. H., \& Schwarzwald, J. (1994). Influence strategies in dating relationship: the effects of relationship satisfaction, gender, and perspective. Journal of Social Behavior and Personality, 9, 429 - 442.

Buehlman, K. T., Gottman, J. M., \& Katz, L. F. (1992). How a couple views their past predicts their future. Journal of Family Psychology, 5, 295-318. doi: http://dx.doi.org/10.1037/0893-3200.5.3-4.295.

Burton, J. (1990). Conflict: Human needs theory. Springer.

Canary, D. J., Cupach, W. R., \& Serpe, R. T. (2001). A competence-based approach to examining interpersonal conflict test of a longitudinal model. Communication Research, 28(1), 79-104.

doi: $10.1177 / 009365001028001003$.

Cutuli, D. (2014). Cognitive reappraisal and expressive suppression strategies role in the emotion regulation: an overview on their modulatory effects and neural correlates. Frontiers in Systems Neuroscience, 8.

175doi: 10.3389/fnsys.2014.00175

De Dreu, C. K. W., Koole, S. L., \& Oldersma, F. L. (1999). On the seizing and freezing of negotiator inferences: Need for cognitive closure moderates the use of heuristics in negotiation. Personality \& Social Psychology Bulletin, 25, 348-362. doi: 10.1177/0146167299025003007

De Rivera, J. H., (1977). A structural theory of the emotions. New York: International Universities Press.

De Rivera J. H., \& Grinkis, C. (1986). Emotions as social relationships. Motivation and Emotion, 10, 351-369. doi:10.1007/BF00992109.

De Rivera, J. H., Possell, L., Verette, J. A., \& Weiner, B. (1989). Distinguishing elation, gladness and joy. Journal of Personality and Social Psychology, 57, 1015-1023.

Forgas, J. P. (1995). Mood and judgment: the affect infusion model (AIM). Psychological bulletin, 117(1), 39-66. doi: http://dx.doi.org/10.1037/0033-2909.117.1.39

Frijda, N. H. (1986). The emotions: Studies in emotion and social interaction. Paris: Maison de Sciences de l'Homme.

Golec, A., \& Federico, C. M. (2004). Understanding Responses to Political Conflict: Interactive effects of the Need for Closure and Salient Conflict Schemas. Journal of Personality and Social Psychology, 87, 750-762.

doi: http://dx.doi.org/10.1037/0022-3514.87.6.750

Gottman, J. M., Coan, J., Carrere, S., \& Swanson, C. (1998). Predicting marital happiness and stability from newlywed interactions. Journal of Marriage and the Family, 5-22. doi:10.2307/353438

Gottman, J., Markman, H., \& Notarius, C. (1977). The topography of marital conflict: A sequential analysis of verbal and nonverbal behavior. Journal of Marriage and the Family, 39, 461-477. doi:10.2307/350902.

Gratz, K. L., \& Tull, M. T. (2010). Emotion regulation as a mechanism of change in acceptance-and mindfulnessbased treatments. Assessing mindfulness and acceptance processes in clients: Illuminating the theory and practice of change, 107-133.

Gross, J. (1998). Antecedent-and response-focused emotion regulation: Divergent consequences for experience, expression, and physiology. Journal of Personality and Social Psychology, 74, 224-237. doi: 10.1037/00223514.74.1.224.

Gross, J. J. (2002). Emotion regulation: Affective, cognitive, and social consequences. Psychophysiology, 39(3), 281291. doi: $10.1017 / \mathrm{S} 0048577201393198$

Igbo, H. I., Grace, A. R., \& Christiana, E. O. (2015). Relationship between Duration of Marriage, Personality Trait, Gender and Conflict Resolution Strategies of Spouses. Procedia-Social and Behavioral Sciences, 190, $490-496$. doi:10.1016/j.sbspro.2015.05.032

Kamphuis, J. H., \& Telch, M. J. (2000). Effects of distraction and guided threat reappraisal on fear reduction during exposure-based treatments for specific fears. Behaviour research and therapy, 38(12), 1163-1181. doi: http://dx.doi.org/10.1016/S0005-7967(99)00147-3 
Kirchler, E. (2001). Conflict and decision-making in close relationships: Love, money, and daily routines. Psychology Press.

Koslowsky, M., \& Schwarzwald, J. (2001). The power interaction model: theory, methodology and empirical application. In A. Y. Lee-Chai, \& J. A. Bargh (Eds.), The use and abuse of power. (pp. 195 - 214). PA: Psychology Press.

Koslowsky, M. \& Schwarzwald, J. (2009). Power tactics preference in organizations: Individual and situational factors. In D. Tjosvold \& B. von Kipppenberg (Eds.), Power and independence in organizations. Cambridge: Cambridge University Press.

Koval, P., Butler, E. A., Hollenstein, T., Lanteigne, D., \& Kuppens, P. (2014). Emotion regulation and the temporal dynamics of emotions: Effects of cognitive reappraisal and expressive suppression on emotional inertia. Cognition \& Emotion, 29(5), 831-851. doi:10.1080/02699931.2014.948388.

Kruglanski, A.W.(2004). The psychology of closed-mindedness. New York: Psychology Press.

Laslo-Roth, R, \& Schwarzwald, J. (2016). Rationale and emotion in the selection of influence tactics by managers in conflict with subordinates. Leadership \& Organization Development Journal, 37(1), 42-70. doi: http://dx.doi.org/10.1108/LODJ-04-2014-0076

Lipovetzky, N., Hod, H., Roth, A., Kishon, Y., Sclarovsky, S., \& Green, M. S. (2007). Emotional Events and Anger at the Workplace as Triggers for a First Event of the Acute Coronary Syndrome: A Case-Crossover Study. IMAJ, 9, 310315.

Montes, C., Rodríguez, D., \& Serrano, G. (2012). Affective choice of conflict management styles. International Journal of Conflict Management, 23(1), 6-18. doi: http://dx.doi.org/10.1108/10444061211199304.

Morris, M. W., \& Keltner, D. (2000). How emotions work: The social functions of emotional expression in negotiations. Research in organizational behavior, 22, 1-50. doi: 10.1016/S0191-3085(00)22002-9.

Pierro, A., \& Kruglanski, A. W. (2005). Revised need for cognitive closure scale. Unpublished manuscript, Università di Roma, La Sapienza.

Raven, B. H. (1992). A power/interaction model of interpersonal influence: French and Raven thirty years later. Journal of Social Behavior and Personality, 7, 217 - 244.

Pierro, A., Kruglanski, A. W., \& Raven, B. H. (2012). Motivational underpinnings of social influence in work settings: Bases of social power and the need for cognitive closure. European Journal of Social Psychology, 42(1), 4152. doi: $10.1002 /$ ejsp.836.

Raven, B. H., Schwarzwald, J., \& Koslowsky, M. (1998). Conceptualizing and measuring a power/interaction model of interpersonal influence. Journal of Applied Social Psychology, 28, 307-332. doi: 10.1111/j.15591816.1998.tb01708.x

Ray, R. D., Ochsner, K. N., Cooper, J. C., Robertson, E. R., Gabrieli, J. D., \& Gross, J. J. (2005). Individual differences in trait rumination and the neural systems supporting cognitive reappraisal. Cognitive, Affective, \& Behavioral Neuroscience, 5(2), 156-168.

Reeck, C., Ames, D. R., \& Ochsner, K. N. (2016). The social regulation of emotion: An integrative, cross-disciplinary model. Trends in cognitive sciences, 20(1), 47-63. doi: http://dx.doi.org/10.1016/j.tics.2015.09.003

Richards, J. M., Butler, E. A., \& Gross, J. J. (2003). Emotion regulation in romantic relationships: The cognitive consequences of concealing feelings. Journal of Social and Personal Relationships, 20(5), 599-620. doi: $10.1177 / 02654075030205002$

Schwarzwald, J., Koslowsky, M., \& Allouf, M. (2005). Group membership, status, and social power preference. Journal of Applied Social Psychology, 35, 644-655. 10.1111/j.1559-1816.2005.tb02139.x

Schwarzwald, J., Koslowsky, M., \& Ben Izhak-Nir, E. B. (2008). Gender role ideology as a moderator of the relationship between social power tactics and marital satisfaction. Sex Roles, 59(9-10), 657-669.

doi:10.1007/s11199-008-9454-y.

Shan, J. Y., Kruglanski, A.W., \& Thompson, E. P. (1998). Membership Has Its (Epistemic) Rewards: Need for Closure Effects on In-Group Bias. Journal of Personality and Social Psychology,75, 383-393. doi: http://dx.doi.org/10.1037/0022-3514.75.2.383

Stifter, C. A., Spinrad, T., \& Braungart-Rieker, J. (1999). Toward a developmental model of child compliance: The role of emotion regulation in infancy. Child Development, 70(1), 21-32. doi: 10.1111/1467-8624.00003 
Tal, A., Schwarzwald, J., \& Koslowsky, M. (2015). Power preference of bank managers in conflicts with subordinates. International Journal of Conflict Management, 26(2), 126-144. doi:

http://dx.doi.org/10.1108/IJCMA-01-2013-0005.

Trautwein, F. M., Naranjo, J. R., \& Schmidt, S. (2016). Decentering the self? Preliminary evidence for changes in self-vs. other related processing as a long-term outcome of loving-kindness meditation. Frontiers in Psychology, 7, 1785. doi: http://dx.doi.org/10.3389/fpsyg.2016.01785.

Van Kleef, G. A., De Dreu, C. K., \& Manstead, A. S. (2004). The interpersonal effects of emotions in negotiations: a motivated information processing approach. Journal of personality and social psychology, 87(4), 510-528. doi: 10.1037/0022-3514.87.4.510.

Watson, D., Clark, L. A. \& Tellegen, A. (1988). Development and validation of brief measures of positive and negative affect: The PANAS scales. Journal of Personality and Social Psychology, 54, 1063-1070. doi: http://dx.doi.org/10.1037/0022-3514.54.6.1063

Webster, D. M., \& Kruglanski, A. W. (1994). Individual differences in need for cognitive closure. Journal of personality and social psychology, 67(6), 1049. doi: http://dx.doi.org/10.1037/0022-3514.67.6.1049

Table 1.

Means, (SDs), and Pearson correlations between the research variables.

\begin{tabular}{|c|c|c|c|c|c|c|c|c|}
\hline & $\begin{array}{c}\text { Mean } \\
\text { (SD) }\end{array}$ & Age & $\begin{array}{l}\text { Relationship } \\
\text { length }\end{array}$ & $\begin{array}{l}\text { Conflict } \\
\text { severity }\end{array}$ & $\begin{array}{c}\text { Harsh } \\
\text { strategy } \\
\text { score }\end{array}$ & $\begin{array}{c}\text { Soft } \\
\text { strategy } \\
\text { score }\end{array}$ & $\begin{array}{c}\text { Negative } \\
\text { affect }\end{array}$ & $\begin{array}{c}\text { Positive } \\
\text { affect }\end{array}$ \\
\hline Age & $\begin{array}{c}88.33 \\
(125.53)\end{array}$ & - & & & & & & \\
\hline $\begin{array}{l}\text { Relationship } \\
\text { length }\end{array}$ & $\begin{array}{c}66.06 \\
(26.48)\end{array}$ & $.881^{* *}$ & - & & & & & \\
\hline Conflict severity & $\begin{array}{c}3.09 \\
(1.11)\end{array}$ & .058 & .006 & - & & & & \\
\hline $\begin{array}{l}\text { Harsh strategy } \\
\text { score }\end{array}$ & $\begin{array}{c}3.95 \\
(1.06)\end{array}$ & -.040 & -.030 & .188 & - & & & \\
\hline $\begin{array}{l}\text { Soft strategy } \\
\text { score }\end{array}$ & $\begin{array}{c}2.54 \\
(0.79)\end{array}$ & -.009 & -.012 & .119 & $.707^{* *}$ & - & & \\
\hline Negative affect & $\begin{array}{c}3.09 \\
(0.77)\end{array}$ & -.021 & -.073 & .155 & $.245^{* *}$ & .121 & - & \\
\hline Positive affect & $\begin{array}{c}3.48 \\
(0.63)\end{array}$ & .170 & $.226^{\mathrm{a}}$ & .124 & -.195 & -.058 & .056 & - \\
\hline $\begin{array}{l}\text { Cognitive } \\
\text { closure }\end{array}$ & $\begin{array}{c}88.33 \\
(125.53)\end{array}$ & .061 & .087 & .042 & -.004 & .038 & .077 & $.296^{*}$ \\
\hline
\end{tabular}

Note. ${ }^{*} \mathbf{p}<.05,{ }^{* *} \mathbf{p}<.01,{ }^{\text {ap }}<.07$. 
Table 2.

Adjusted means (and SEs), and ANCOVA values for the differences between the emotion regulation manipulation groups, with strategy, affect and cognitive closure as dependent variables.

\begin{tabular}{lccccccc}
\hline \multirow{2}{*}{ Dependent variables } & \multicolumn{2}{c}{ Group } & & \multicolumn{3}{c}{ ANCOVA $^{\text {anc }}$} \\
\cline { 2 - 3 } \cline { 6 - 8 } & Reappraisal & Control & & $F$ & $p$ & $\eta^{2}$ \\
\hline Harsh strategy score & $3.47(0.18)$ & $2.72(0.18)$ & & 8.7 & 0.004 & 0.115 \\
Soft strategy score & $4.27(0.18)$ & $3.65(0.17)$ & & 6.22 & 0.015 & 0.085 \\
Negative affect & $2.46(0.14)$ & $2.62(0.12)$ & & 0.75 & 0.389 & 0.011 \\
Positive affect & $3.01(0.13)$ & $3.17(0.13)$ & & 0.76 & 0.386 & 0.011 \\
Cognitive closure & $3.63(0.11)$ & $3.35(0.10)$ & & 3.37 & 0.036 & 0.048 \\
\hline
\end{tabular}

Note, aControlling for conflict severity $(M=66.06)$. 


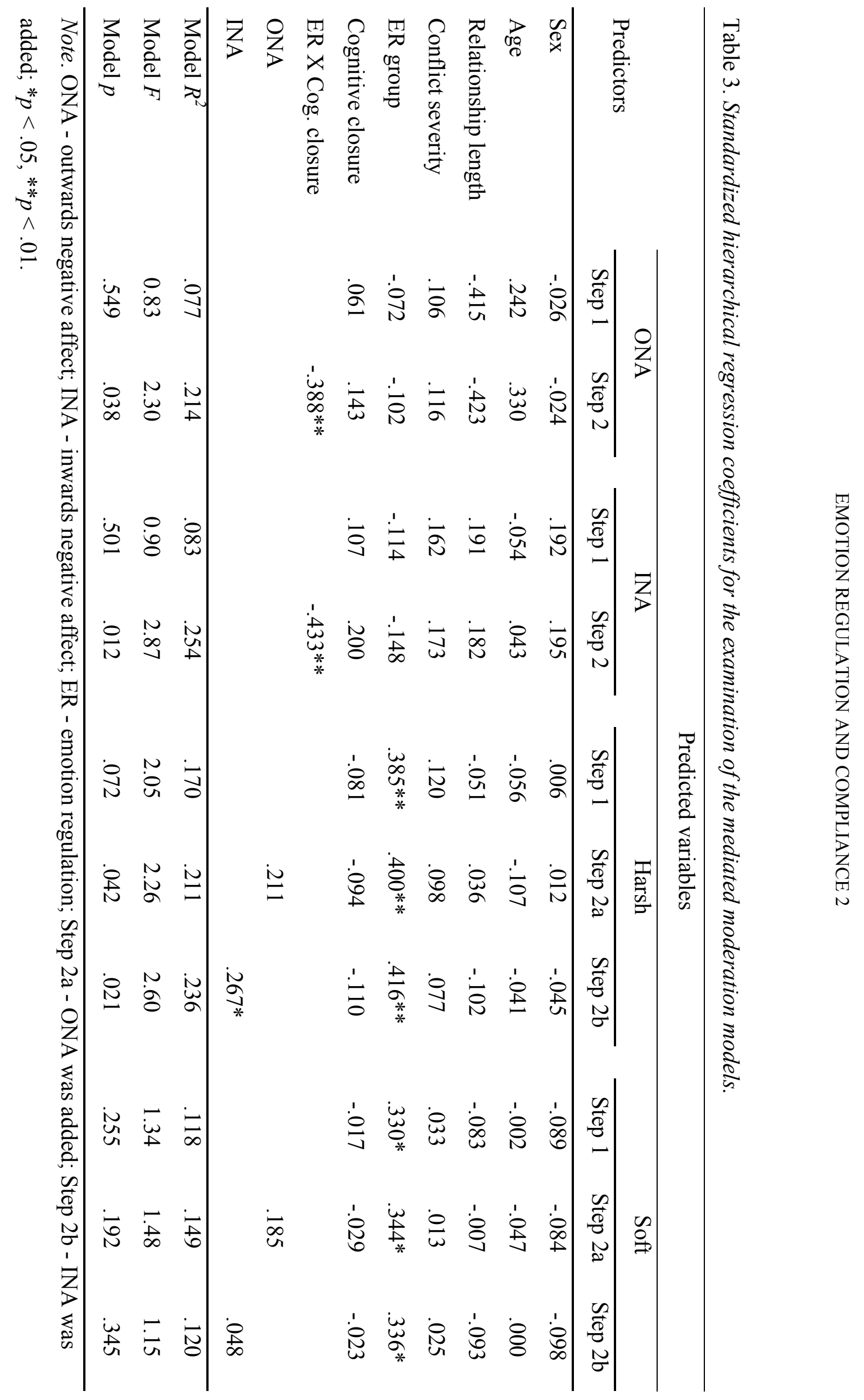




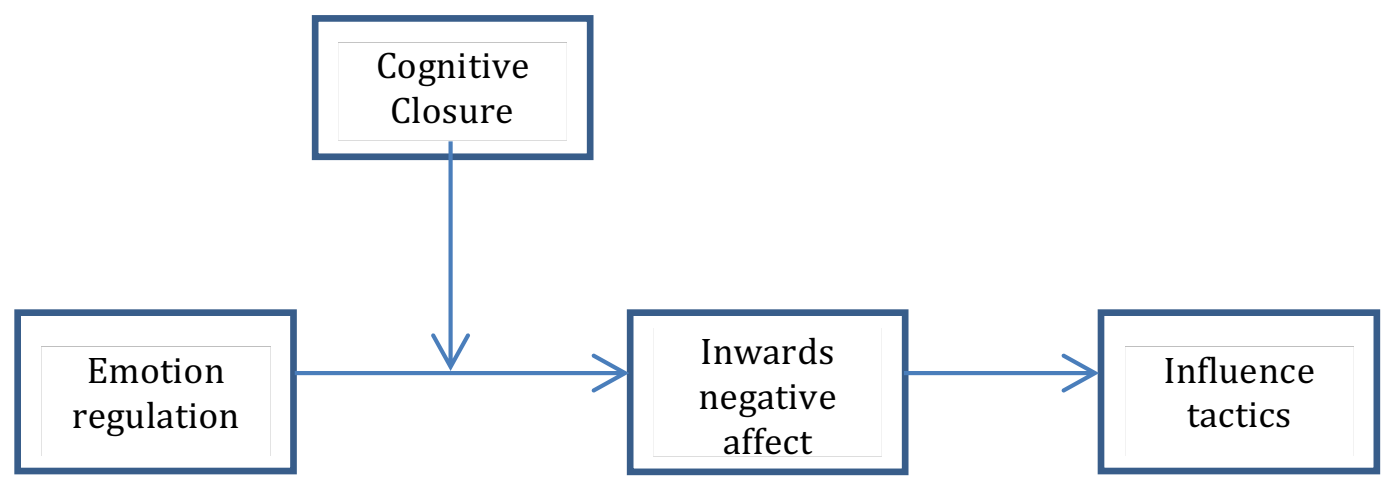

Figure 1. Predicted mediated moderation model. The moderation effect of cognitive closure on emotion regulation was predicted to be mediated by inwards negative affect.

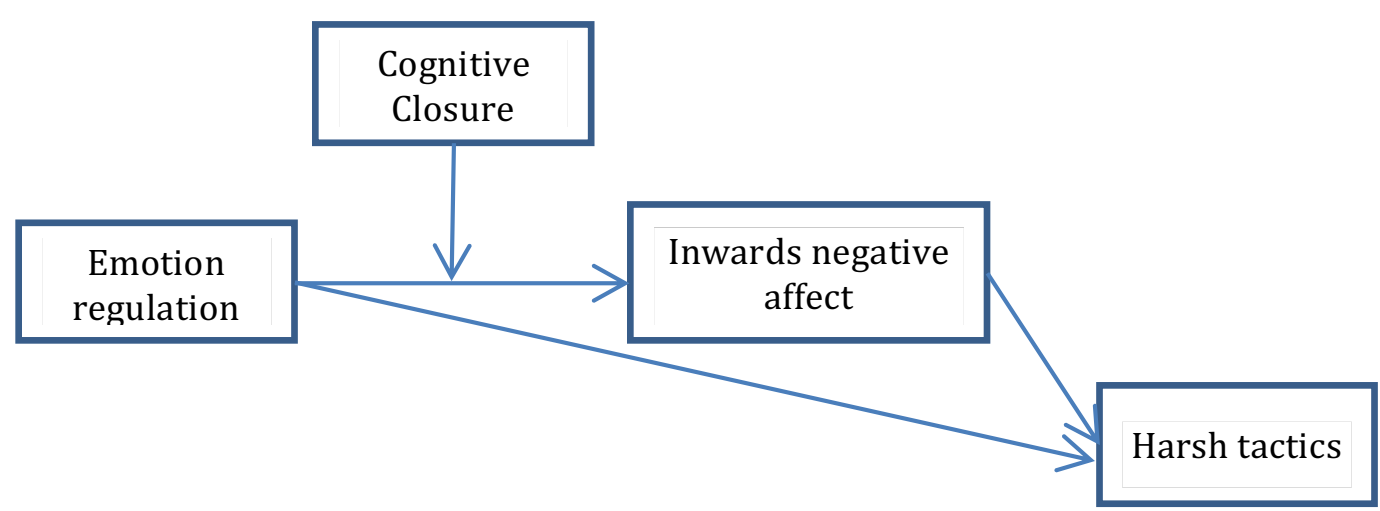

Figure 2. The final mediated moderation model observed in the study. Adaptive emotion regulation affected the compliance with harsh tactics through two distinct pathways. First, adaptive emotion regulation increased compliance directly. Second, it interacted with cognitive closure to reduce the inwards negative affect rates, which in turn affected the compliance with harsh tactics. 